\title{
Trends in US dust frequency and intensity: role of climate and local meteorology
}

\author{
YOG ARYAL AND STUART EVANS
}

The State University of New York(SUNY) at Buffalo

Presenting Author: yogaryal@buffalo.edu

Dust over the Western US (WUS) exhibits large trends and interannual variability, with complex links between the WUS dust cycle and climatic as well as local meteorological and surface conditions. Both the occurrence frequencies of dust events and the intensities of those dust events contribute to the temporal trends and the interannual variability of the WUS dust.. Using the observed daily dust deposition during 1988-2020 from the Interagency Monitoring of Protected Visual Environments (IMPROVE) network, we examine the overall temporal trend in seasonal dustiness in terms of both event frequency and their intensities. The linear regression method is used to estimate the linear trends in dust and their relation with climatic and meteorological conditions. Results show that there is a significant decreasing trend in the occurrence frequency of highintensity dust events (dust events greater than the $90^{\text {th }}$ percentile of intensity) while the frequency of low-intensity dust events (dust events less than the $25^{\text {th }}$ percentile of intensity) show significant increasing trends over the WUS. We examine several intensity categories, and in general, the weaker the dust event threshold the greater the positive trend in the frequency of occurrence, and the stronger the dust event the more negative the trend. In addition, the intensity of dust events, i.e. what constitutes a $90^{\text {th }}$ or $25^{\text {th }}$ percentile event each year, has negative trends for both high-intensity and low-intensity dust events. By comparing these trends and variability to atmospheric and surface conditions such as wind speed, wind gust strength, and soil water we are able to identify the local meteorological and surface conditions that control the dust cycle. 